\title{
Sensing viral invasion by RIG-I like receptors.
}

$\operatorname{AUTHOR}(\mathrm{S})$ :

Yoo, Ji-Seung; Kato, Hiroki; Fujita, Takashi

CITATION:

Yoo, Ji-Seung ...[et al]. Sensing viral invasion by RIG-I like receptors..

Current opinion in microbiology 2014, 20: 131-138

ISSUE DATE:

2014-08

URL:

http://hdl.handle.net/2433/189083

RIGHT:

(C) 2014 Elsevier Ltd.; This is not the published version. Please cite only the published version.; この論文は出版社版でありません。引用の際に は出版社版をご確認ご利用ください。 


\section{Sensing viral invasion by RIG-I like receptors}

Ji-Seung Yoo ${ }^{1,2}$, Hiroki Kato ${ }^{1,2}$, and Takashi Fujita ${ }^{1,2}$

1: Laboratory of Molecular Genetics, Institute for Virus Research, Kyoto University, Kyoto, Japan

2: Laboratory of Molecular Cell Biology, Graduate School of Biostudies, Kyoto University, Kyoto, Japan

\section{Corresponding Author:}

Takashi Fujita, Ph.D

tfujita@virus.kyoto-u.ac.jp

Phone/Fax: 81-75-751-4031 


\begin{abstract}
Cellular responses to pathogen invasion are crucial for maintaining cell homeostasis and survival. The interferon (IFN) system is one of the most effective cellular responses to viral intrusion in mammals. Viral recognition by innate immune sensors activates the antiviral IFN system. Retinoic acid-inducible gene I (RIG-I) like receptors (RLRs) are DExD/H box RNA helicases that sense viral invasion. RLRs recognize cytoplasmic viral RNAs and trigger antiviral responses, resulting in production of type I IFN and inflammatory cytokines. Unique and common sensing mechanisms among RLRs have been reported. In this review, recent progress in the understanding of antiviral responses by RLRs is summarized and discussed.
\end{abstract}




\section{Introduction}

Virus infection induces numerous host responses to eliminate pathogen invasion. Host antiviral responses are operated by germline-encoded cellular receptors that recognize specific patterns of foreign molecules, termed pathogen-associated molecular patterns (PAMPs). PAMPs are detected by the 'sensor' molecules, known as pattern recognition receptors (PRRs), which play a crucial role in triggering host innate immunity, a primary cellular defense system. Recent studies have identified several innate immune receptors including Toll-like receptors (TLRs), nucleotide-binding oligomerization domain (NOD)-like receptors (NLRs) and RLRs, and clarified their roles in antiviral signaling by sensing virus-derived molecules.

In this review, we focus on RLRs, which detect cytoplasmic viral RNA PAMPS. For the function of TLRs and NLRs, refer to reviews published elsewhere [1] [2].

\section{RLR-mediated signaling}

RLRs are Asp-Glu-Ala-Asp (DEAD) box containing RNA helicases. To date, three members including RIG-I, melanoma differentiation-associated gene 5 (MDA5) and laboratory of genetics and physiology 2 (LGP2) have been indentified. All RLRs share helicase domain and C-terminal domain (CTD), however LGP2 lacks a caspase activation and recruitment domain (CARD), that is critical for signal transduction; thus, LGP2 has been suggested as the regulatory molecule for RIG-I and MDA5 [3] [4].

Upon viral infection, RLRs recognize PAMP RNAs (Table 1) and undergo conformational change mediated by ATPase/Helicase activity, which results in the exposure of CARD [5] [6]. Although RIG-I and MDA5 sense distinct viral infections [7] (Table 2), they share a common mitochondria-localized downstream signal adaptor, interferon promoter stimulator-1 (IPS-1, also termed MAVS, VISA or Cardif) for signal transduction [8]. Upon interaction between RLR and IPS-1 via their CARD-CARD association, IPS-1 conforms aggregates which share several features of prions [9]. The mitochondrial component, mitofusin 1 (MFN1) plays a critical role in the IPS-1 aggregation by 
regulation of the mitochondrial fusion and fission [10]. This assembly further results in the recruitment of several ubiquitin ligases (TRAFs) and kinase complexes (TBK1 or IKK $\varepsilon$ and IKK $\alpha / \beta / \gamma \square$ comple $\square$.A recent study suggested that $\boxminus \mathbb{G}, E$ Fmicrotubule network-associated protein, regulates the trafficking of IFN signaling by mediating the interaction between TBK1/IKK $\varepsilon \square$ and IRF3[11]. Eventually, the activation of transcription factors IRF3 and IRF7, as well as NF- $\square$ B, leads to the production of type I IFNs and pro-inflammatory cytokines [8] (Figure 1).

The produced IFN becomes a messenger of the 'warning sign' for both IFN-producing and bystander cells, and promotes the 'second round' antiviral responses by inducing the expression of hundreds of interferon-stimulated genes (ISGs). The antiviral roles of several representative ISGs, such as PKR, OASs and RNase L, are well-characterized. Recent studies further elucidated the function of another ISG, IFITs, in their antiviral activity. IFITs, especially IFIT1, IFIT2 and IFIT5, recognize 5' triphosphorylated (5' ppp) RNA or capped RNA lacking 2'-O-methyl groups and sequester such RNA from translation, leading to the inhibition of viral replication [12] [13].

\section{RNA ligands of RIG-I}

1. Does RIG-I recognize RNA with 5'-triphosphate?

In 2006, two groups simultaneously provided significant evidence that triphosphate moiety on the 5' end is an essential determinant of RIG-I activation using single-stranded (ss) 'in vitro transcribed' RNA (ivtRNA) or a viral genome containing 5'ppp [14] [15] [16]. Rehwinkel et al. also proved that viral genomes bearing 5'ppp trigger IFN responses [17]. However, it became clearer in the following two studies that 5'ppp itself is not sufficient for efficient RIG-I activation [18] [19]. These reports commonly found that, unlike 5'ppp ivtRNA, chemically synthesized 5'ppp ssRNA did not activate RIG-I and they also realized that products of in vitro transcription by phage RNA polymerase retained the unexpected 'copy-back' structure. Therefore they concluded that an additional double-stranded region or a stem-loop structure is necessary for a true RIG-I agonist. Indeed, it was clarified that Sendai virus (SeV) and 
vesicular stomatitis virus (VSV) produce RIG-I agonist RNA, known as a 'defective-interfering (DI) RNA', which contains a copy-back structure with 5'ppp [20] [21]. Moreover, recent studies showed that PAMP RNA from negative-strand ssRNA viruses, including influenza A, rabies, and measles virus, possess conserved panhandle structures with 5'ppp in their genomes, further confirming that 5'ppp along with secondary structures is an indispensable characteristic of RIG-I activators.

\section{2. dsRNA activates RLRs}

dsRNA is a classical non-self RNA, which is not produced in uninfected cells due to a lack of RNA-dependent RNA polymerase in mammalian cells. Both RIG-I and MDA5 appear to regulate the induction of type I IFN after stimulation by dsRNA [22]. Since artificial dsRNA, polyinosinic:polycytidylic acid (poly I:C), does not possess 5' triphosphate, several studies using various 5'- or 3'-modified dsRNAs also showed that 5'ppp is dispensable for RIG-I activation [5] [23]; it is generally assumed that recognition of dsRNA by RIG-I does not require 5'ppp. Interestingly, it was discovered that the length of dsRNA is a critical determinant that enables RNA ligands to turn on either RIG-I or MDA5 activation [24]. It was revealed that short dsRNA $(<1 \mathrm{~kb})$ elicited IFN production through RIG-I while long dsRNA ( $>7 \mathrm{~kb}$ ) failed to activate RIG-I, but efficiently activate MDA5. Related to the size-dependent activation of RIG-I by dsRNA, it is suggested that RIG-I conforms to a different structure when bound to short and long dsRNA [5].

The dsRNA chain length-dependent recognition was confirmed by viral infection [24]. For example, viruses that produce undetectable (Influenza A virus) or short dsRNA (VSV) activate RIG-I-dependent signaling. In contrast, long dsRNA-producing viruses, such as encephalomyocarditis virus (EMCV) induce IFN signaling through MDA5. Interestingly, reovirus, whose genome is composed of different-sized segmented dsRNA, is recognized by both RIG-I and MDA5 [24].

\section{RNA sequence specificity}

Although sensing of dsRNA does not seem to require sequence specificity, the RNA sequence is an important feature for the recognition of 5'ppp RNAs by 
RIG-I. Saito et al. found that 3'-untranslated region (3' UTR) of the hepatitis C virus (HCV) genome (SSRNA) is a potent RIG-I activator [25]. On screening of the RIG-I activating domain by dissecting the HCV 3'UTR, they discovered that the uridine-rich region has the potential to trigger IFN signaling through RIG-I in a 5'ppp dependent manner. Nucleotide substitution analysis further revealed that adenosine-rich RNA also potentially activates RIG-I. Moreover, the authors also showed that IFN induction by the full-length HCV genome is dependent on 3'UTR in vivo, confirming that the uridine-rich sequence is a crucial PAMP for the recognition of HCV by RIG-I.

\section{PAMP production by host enzymes}

In 2009, two groups simultaneously reported that AT-rich dsDNA triggers IFN signaling through the RIG-I pathway [26] [27]. It was discovered that AT-rich, but not GC- or IC-rich dsDNA, is a template for RNA polymerase III that produces 5'ppp-containing AU-rich RNA. Since transcription may occur for both strands of a template, RNA transcripts are perfectly complementary, producing 5'ppp-dsRNA.

By definition, 'non-self RNAs' are derived from a pathogen, however, one report suggests the conversion of 'self RNAs' into immune-stimulatory molecules. Malathi et al. discovered that small RNAs produced from the cleavage of both viral and host RNA by RNase $L$ can activate interferon signaling through both RIG-I and MDA5 [28]. Cleaved products are small RNAs (< 200 nt) with 5'-hydroxyl (5'-OH) and 3'-monophosphoryl (3'-P) groups. Interestingly, loss of 3'-monophosphate abolished its ability to activate RLR, suggesting a 3'-monophosphate-dependent sensing mechanism for RLR signaling. The authors further suggested the requirement of a higher order structure in addition to 3'-P for this regulation [29].

\section{RNA ligands of MDA5}

1. MDA5 recognizes long dsRNA

Compare to RIG-I ligands, very little is known about the biochemical specificities of 'MDA5-activating' RNA ligands. To date, several approaches 
have elucidated that MDA5 mainly senses positive single-stranded RNA or dsRNA viruses, such as Picornaviridae, Caliciviridae, Togaviridae, Flaviviridae, and Reoviridae. While IFN induction by Picornaviridae and Caliciviridae exclusively detected by MDA5 [7] [30], MDA5 is partially involved in antiviral responses induced by Togaviridae [31], Flaviviridae [32] and Reoviridae [24]. These viruses produce or possess 'long dsRNA' and this is consistent with the central concept that MDA5 senses long dsRNA. Recently, Feng et al. suggested that MDA5 senses neither genomic RNA nor viral mRNA, but recognizes 'replication intermediates' generated during minus-strand RNA synthesis [33], further supporting the idea that long dsRNA is a critical determinant of an MDA5 ligands.

\section{RNA web}

In addition to length dependency, there is another hallmark of MDA5 ligand in relation to the RNA structure. Recently, Pichlmair et al. suggested the new concept that activation of MDA5 requires a 'high-order' RNA structure [34]. Interestingly, 'pure' long dsRNA (> $10 \mathrm{~kb}$ ) generated by the viruses such as EMCV or vaccinia virus (VV) does not trigger IFN expression even though MDA5 interacts with it. However, 'high molecular weight' viral RNA that contains both ssRNA and dsRNA, robustly induces innate immune responses. Since MDA5 recognition of these RNAs does not require sequence specificity, they concluded that MDA5 activation requires an 'RNA web' rather than just 'simply long' dsRNA. Since this result was confirmed with natural viral RNA, their finding may provide a significant clue for the identification of natural MDA5 ligand.

\section{Cooperation of RNase L for MDA5 sensing} Interestingly, there is a recent report showing that MDA5 can recognize viral mRNA and induce IFN signaling. Luthra et al. showed that parainfluenza virus 5 (PIV5) mRNA coding $L$ protein can be converted to a potent MDA5 ligand by RNase $L$ [35]. It is of interest to note that only a specific region of viral mRNA cleaved by RNase $L$ activates MDA5, suggesting that MDA5 requires a specific RNA sequence or structure for recognition. 


\section{Contribution of LGP2 to RLR sensing}

Compared to other RLRs, the functional role of LGP2 in viral recognition is still not well understood. LGP2 was originally thought to function as a negative regulator of RLR signaling due to the lack of the signaling domain, CARDs [3]. Indeed, several earlier reports showed the negative regulation of RLR signaling by overexpression of LGP2 [3] [36]. However, two recent independent studies using a 'LGP2-knockout' system suggested a positive role of LGP2 in RLR sensing [4] [37]. These two studies confirmed impaired IFN production in LGP2-deficient cells by picornavirus, indicating that LGP2 functions positively in MDA5-derived IFN signaling. However, the functional role of LGP2 in RIG-I-induced antiviral responses is inconsistent with these studies; thus, the contribution of LGP2 to sensing by RIG-I is controversial. It is proposed that LGP2 may cooperate with either MDA5 or RIG-I to transmit a signal to IPS-1 through their CARDs. Interestingly, LGP2 is dispensable for IFN production by synthetic RNA molecules such as poly I:C and 5'ppp RNA. Although ATPase activity of LGP2 is essential for this regulation [4], the exact mechanism of LGP2-mediated augmentation remains to be clarified.

\section{Post-translational modification: the mainspring of RLR signaling} Upon viral infection, antiviral IFN signaling is immediately propagated through the cooperative association of multiple antiviral molecules. During the signaling cascade, antiviral proteins undergo various biochemical or physical modifications, such as oligomerization, ubiquitination and phosphorylation.

It was reported that RIG-I and MDA5 are oligomerized upon ligand recognition. Indeed, artificial oligomerization of RIG-I using a chemical cross linker can activate an antiviral response without a virus or dsRNA stimulus [38]. Recent studies suggested that oligomerization of RIG-I occurs through its ATPase activity and is required for optimal RIG-I activation [39] [40]. Peisley et al. showed that RIG-I binds to the end region of dSRNA without ATP hydrolysis but upon ATP treatment, RIG-I forms a 'filament-like' oligomer along dsRNA [40]. Unlike RIG-I, however, MDA5 is capable of assembling a filament in an ATP-independent manner, suggesting distinct sensing mechanisms between 
RIG-I and MDA5 [41]. In addition, Jiang et al. reported that lysine-63 (K63) poly-ubiquitination on the CARD domain induces a hetero-tetrameric complex of RIG-I and further elucidated that ubiquitin-induced RLR oligomerization is critical for downstream signal transduction [42]. Thus, oligomerization of RLR is a significant hallmark of RLR activation.

The importance of K63 poly-ubuquitination on RIG-I by ubiquitin ligases TRIM25 and Riplet has been previously reported [43] [44]. Indeed, multiple ubiquitin ligases are involved in the regulation of innate immune signaling [45]. Upon K63 ubiquitination-mediated RIG-I/IPS-1 interaction, IPS-1 forms a fibril-like structure that converts 'normal' IPS-1 to 'functional' IPS-1, thus termed 'prion-like-aggregates', leading to the propagation of antiviral signaling [9]. Thus, ubiquitination seems to be a critical post-translational modification for governing the antiviral signaling from 'RLR activation' to 'signal transduction'.

Phosphorylation is one of the best-studied post-translational modifications that switch many cellular signaling pathways on and off. Indeed, several kinases are involved in IFN signaling and play crucial roles in host antiviral responses. dsRNA-dependent protein kinase (PKR) is a classic IFN-inducible antiviral protein that comprises a dsRNA-binding motif and a kinase domain [46]. Recently, it was suggested that PKR is a key factor for the induction of cytoplasmic bodies called 'stress granule' (SG) by viral infection and we further demonstrated that SGs provide a critical platform for interactions between antiviral proteins, including RLRs, DHX36, RNase L and OAS1, and non-self RNA ligands, thus termed 'antiviral stress granule' (avSG) [47] [48] [49] [50] (Figure 1) More recently, it was shown that the ubiquitin ligases TRIM25 and Riplet are co-localized with SG after viral infection or poly I:C transfection, further suggesting the significant role of avSG in RLR signal transduction [50] [44] (Figure 1).

\section{Viral evasion of RLR sensing}

The loser of the battle between a virus and host will face a 'dead-end', thus 
arming it with a better strategy that is essential for survival. Recent reports showed multiple strategies of viruses to evade RLR sensing by encoding suppressors that target signaling molecules in antiviral responses.

Several viral proteins directly target RLRs. For example, influenza virus NS1, a multifunctional antagonist of host immune responses [51], inhibits ubiquitination of RIG-I CARD by interrupting TRIM25 [52]. In addition, hijacking of RIG-I and TRIM25 by viral protein abrogates IFN signaling [53]. Moreover, it is known that $\mathrm{V}$ protein of paramyxoviridae member viruses directly binds to MDA5 and suppresses the function of MDA5 [54]. Critical signal adaptor, IPS-1 is also an attractive target of HCV that induce cleavage of IPS-1 by viral protease, NS3/4A [55]. Furthermore, function of downstream signal molecules such as TBK1 and IRF3 is also hampered by viral infection [56] [57] [58].

In addition to direct inhibition of the signaling molecules, several viruses also counteract IFN production by preventing or disrupting the formation of avSG. It is reported that influenza viral protein NS1 inhibits PKR activation to prevent avSG formation [47] [59]. EMCV also blocks antiviral signaling by disrupting avSG through cleavage of G3BP by viral protease 3C [48]. Furthermore, several viruses antagonize the induction of avSG formation by preventing dsRNA accumulation that would otherwise induces antiviral signaling [60] [61].

\section{Conclusions}

It has been a decade since the 'long-sought' cytoplasmic viral sensors, RLRs, were identified. During the last decade, numerous efforts by colleagues in this field have advanced our understanding of the cytoplasmic antiviral sensing system. However, there are still unsolved fundamental questions that remain to be addressed.

Although accumulated research has identified the essential properties of RLR-activating ligands, our knowledge is limited due to the physiological differences between 'artificial' and 'natural' RLR agonists. Therefore, it is important to investigate 1) what types of RNA are produced by different viral infections, 2) which RNA molecules from viral replication are truly responsible for RLR activation, 3) what is the exact molecular feature of RLR-activating 
viral RNAs and 4) how each virus evades host immune responses. By understanding these issues, it may be possible to develop 'order-made' antiviral therapeutics or vaccines for 'viral strain-specific' clinical treatment. Another important issue to be considered is that, although major players in IFN signaling have been identified, the molecular mechanisms of signal transduction and termination are still poorly understood. Since autoimmune disorders are often related to the loss of 'self-immune control', understanding the precise molecular mechanisms of the signal transduction may enable us to target specific signal molecules to relieve 'hypersensitive' immune reactions. Finally, it would be also worth connecting RLRs to other applications, for instance, developing anti-cancer or anti-aging treatments for the next decade. 


\section{Acknowledgements}

We thank all colleagues in our laboratory, Dr. M. Yoneyama and Dr. K.

Onomoto for helpful discussions. We also apologize to all of our colleagues in this field whose work could not be cited due to space limitations.

This work was supported in part by research grants Innovative Areas "Infection competency" (No. 24115004) and Scientific Research "A" (No. 23249023) from the Ministry of Education, Culture, Sports, Science and Technology (MEXT) of Japan. The funders had no role in study design, data collection and analysis, preparation of the manuscript, or decision to publish. 


\section{Figure legends}

\section{Figure 1. RLR signal pathway}

Upon viral infection, non-self RNAs, such as 5'ppp-containing structured RNA or dsRNA, are recognized by host cytoplasmic sensors, RLRs and PKR. Recognition of RNA ligands induces conformational changes of RLRs and $\mathrm{PKR}$, leading to the initiation of downstream signaling cascades. Activated PKR immediately induces avSG, where antiviral proteins and signal molecules interact, and augments RLR signaling. E3 ubiquitin ligases-mediated CARD-CARD interaction between RLRs and IPS-1 recruits TRAFs and kinase complexes (TBK1 \& IKKE) to facilitate IRF3 phosphorylation and nuclear translocation, resulting in the expression of type I IFN genes. 


\section{References}

1. Kawai T, Akira S: Toll-like receptors and their crosstalk with other innate receptors in infection and immunity. Immunity (2011) 34(5):637-650.

2. Chen G, Shaw MH, Kim YG, Nunez G: Nod-like receptors: Role in innate immunity and inflammatory disease. Annu Rev Pathol (2009) 4(365-398.

3. Yoneyama M, Kikuchi M, Matsumoto K, Imaizumi T, Miyagishi M, Taira K, Foy E, Loo YM, Gale M, Jr., Akira S, Yonehara S et al: Shared and unique functions of the DExD/H-box helicases RIG-I, MDA5, and LGP2 in antiviral innate immunity. $J$ Immunol (2005) 175(5):2851-2858.

4. Satoh T, Kato H, Kumagai Y, Yoneyama M, Sato S, Matsushita K, Tsujimura T, Fujita T, Akira S, Takeuchi O: LGP2 is a positive regulator of RIG-I- and MDA5-mediated antiviral responses. Proc Natl Acad Sci U S A (2010) 107(4):1512-1517.

5. Takahasi K, Yoneyama M, Nishihori T, Hirai R, Kumeta H, Narita R, Gale M, Jr., Inagaki F, Fujita T: Nonself RNA-sensing mechanism of RIG-I helicase and activation of antiviral immune responses. $\mathrm{Mol}$ Cell (2008) 29(4):428-440.

6. Jiang F, Ramanathan A, Miller MT, Tang GQ, Gale M, Jr., Patel SS, Marcotrigiano J: Structural basis of RNA recognition and activation by innate immune receptor RIG-I. Nature (2011) 479(7373):423-427.

7. Kato H, Takeuchi O, Sato S, Yoneyama M, Yamamoto M, Matsui K, Uematsu S, Jung A, Kawai T, Ishii KJ, Yamaguchi O et al: Differential roles of MDA5 and RIG-I helicases in the recognition of RNA viruses. Nature (2006) 441(7089):101-105.

8. Kawai T, Akira S: The roles of TLRs, RLRs and NLRs in pathogen recognition. Int Immunol (2009) 21(4):317-337.

9. Hou F, Sun L, Zheng H, Skaug B, Jiang QX, Chen ZJ: MAVS forms functional prion-like aggregates to activate and propagate antiviral innate immune response. Cell (2011) 146(3):448-461.

10. Onoguchi K, Onomoto K, Takamatsu S, Jogi M, Takemura A, Morimoto S, Julkunen I, Namiki H, Yoneyama M, Fujita T: Virus-infection or 5'ppp-RNA activates antiviral signal through redistribution of IPS-1 mediated by MFN1. PLoS Pathog (2010) 6(7):e1001012.

11. Chiang HS, Zhao Y, Song JH, Liu S, Wang N, Terhorst C, Sharpe AH, Basavappa M, Jeffrey KL, Reinecker HC: GEF-H1 controls microtubule-dependent sensing of nucleic acids for antiviral host defenses. Nat Immunol (2014) 15(1):63-71. 
12. Habjan M, Hubel $P$, Lacerda L, Benda C, Holze C, Eberl CH, Mann A, Kindler E, Gil-Cruz C, Ziebuhr J, Thiel V et al: Sequestration by IFIT1 impairs translation of 2'O-unmethylated capped RNA. PLOS Pathog (2013) 9(10):e1003663.

- This paper clarified the mechanism of antiviral function of IFIT1 protein.

13. Hyde JL, Gardner CL, Kimura T, White JP, Liu G, Trobaugh DW, Huang C, Tonelli M, Paessler S, Takeda K, Klimstra WB et al: A viral RNA structural element alters host recognition of nonself RNA. Science (2014) 343(6172):783-787.

-. This study revealed the involvement of viral RNA structures for evading host antiviral sensing.

14. Kim DH, Longo M, Han Y, Lundberg P, Cantin E, Rossi JJ: Interferon induction by siRNAs and ssRNAs synthesized by phage polymerase. Nat Biotechnol (2004) 22(3):321-325.

15. Hornung $\mathrm{V}$, Ellegast J, Kim S, Brzozka K, Jung A, Kato H, Poeck H, Akira S, Conzelmann KK, Schlee M, Endres S et al: 5'-triphosphate RNA is the ligand for RIG-I. Science (2006) 314(5801):994-997.

16. Pichlmair A, Schulz O, Tan CP, Naslund TI, Liljestrom P, Weber F, Reis e Sousa C: RIG-I-mediated antiviral responses to single-stranded RNA bearing 5'-phosphates. Science (2006) 314(5801):997-1001.

17. Rehwinkel J, Tan CP, Goubau D, Schulz O, Pichlmair A, Bier K, Robb N, Vreede F, Barclay W, Fodor E, Reis e Sousa C: RIG-I detects viral genomic RNA during negative-strand RNA virus infection. Cell (2010) 140(3):397-408.

18. Schlee M, Roth A, Hornung V, Hagmann CA, Wimmenauer V, Barchet W, Coch C, Janke M, Mihailovic A, Wardle G, Juranek S et al:

Recognition of 5' triphosphate by RIG-I helicase requires short blunt double-stranded RNA as contained in panhandle of negative-strand virus. Immunity (2009) 31(1):25-34.

19. Schmidt A, Schwerd T, Hamm W, Hellmuth JC, Cui S, Wenzel M, Hoffmann FS, Michallet MC, Besch R, Hopfner KP, Endres S et al: 5'-triphosphate RNA requires base-paired structures to activate antiviral signaling via RIG-I. Proc Natl Acad Sci U S A (2009) 106(29):12067-12072.

20. Baum A, Sachidanandam R, Garcia-Sastre A: Preference of RIG-I for short viral RNA molecules in infected cells revealed by next-generation sequencing. Proc Natl Acad Sci U S A (2010) 107(37):16303-16308.

21. Panda D, Dinh PX, Beura LK, Pattnaik AK: Induction of interferon and interferon signaling pathways by replication of defective interfering particle RNA in cells constitutively expressing vesicular stomatitis virus replication proteins. J Virol (2010) 84(9):4826-4831. 
22. Yoneyama M, Kikuchi M, Natsukawa T, Shinobu N, Imaizumi T, Miyagishi M, Taira K, Akira S, Fujita T: The RNA helicase RIG-I has an essential function in double-stranded RNA-induced innate antiviral responses. Nat Immunol (2004) 5(7):730-737.

23. Marques JT, Devosse T, Wang D, Zamanian-Daryoush M, Serbinowski $P$, Hartmann R, Fujita T, Behlke MA, Williams BR: A structural basis for discriminating between self and nonself double-stranded RNAs in mammalian cells. Nat Biotechnol (2006) 24(5):559-565.

24. Kato H, Takeuchi O, Mikamo-Satoh E, Hirai R, Kawai T, Matsushita K, Hiiragi A, Dermody TS, Fujita T, Akira S: Length-dependent recognition of double-stranded ribonucleic acids by retinoic acid-inducible gene-i and melanoma differentiation-associated gene 5. J Exp Med (2008) 205(7):1601-1610.

25. Saito T, Owen DM, Jiang F, Marcotrigiano J, Gale M, Jr.: Innate immunity induced by composition-dependent RIG-I recognition of hepatitis C virus RNA. Nature (2008) 454(7203):523-527.

26. Ablasser A, Bauernfeind F, Hartmann G, Latz E, Fitzgerald KA, Hornung V: RIG-I -dependent sensing of poly(dA:dT) through the induction of an RNA polymerase III-transcribed RNA intermediate. Nat Immunol (2009) 10(10):1065-1072.

27. Chiu YH, Macmillan JB, Chen ZJ: RNA polymerase III detects cytosolic DNA and induces type I interferons through the RIG-I pathway. Cell (2009) 138(3):576-591.

28. Malathi K, Dong B, Gale M, Jr., Silverman RH: Small self-RNA generated by RNase $L$ amplifies antiviral innate immunity. Nature (2007) 448(7155):816-819.

29. Malathi K, Saito T, Crochet N, Barton DJ, Gale M, Jr., Silverman RH: RNase I releases a small RNA from HCV RNA that refolds into a potent PAMP. RNA (2010) 16(11):2108-2119.

30. McCartney SA, Thackray LB, Gitlin L, Gilfillan S, Virgin HW, Colonna M: MDA-5 recognition of a murine norovirus. PLOS Pathog (2008) 4(7):e1000108.

31. Schulz O, Pichlmair A, Rehwinkel J, Rogers NC, Scheuner D, Kato H, Takeuchi O, Akira S, Kaufman RJ, Reis e Sousa C: Protein kinase R contributes to immunity against specific viruses by regulating interferon mRNA integrity. Cell Host Microbe (2010) 7(5):354-361.

32. Loo YM, Fornek J, Crochet N, Bajwa G, Perwitasari O, Martinez-Sobrido L, Akira S, Gill MA, Garcia-Sastre A, Katze MG, Gale $\mathrm{M}$, Jr.: Distinct RIG-I and MDA5 signaling by RNA viruses in innate immunity. J Virol (2008) 82(1):335-345. 
the ubiquitin ligase TRIM25 to evade recognition by the host viral RNA sensor RIG-I. Cell Host Microbe (2009) 5(5):439-449.

53. Santiago FW, Covaleda LM, Sanchez-Aparicio MT, Silvas JA, Diaz-Vizarreta AC, Patel JR, Popov V, Yu XJ, Garcia-Sastre A, Aguilar $P V$ : Hijacking of RIG-I signaling proteins into virus-induced cytoplasmic structures correlates with the inhibition of type I interferon responses. $J$ Virol (2014) 88(8):4572-4585.

54. Motz C, Schuhmann KM, Kirchhofer A, Moldt M, Witte G, Conzelmann KK, Hopfner KP: Paramyxovirus V proteins disrupt the fold of the RNA sensor MDA5 to inhibit antiviral signaling. Science (2013) 339(6120):690-693.

55. Li XD, Sun L, Seth RB, Pineda G, Chen ZJ: Hepatitis C virus protease NS3/4A cleaves mitochondrial antiviral signaling protein off the mitochondria to evade innate immunity. Proc Natl Acad Sci U S A (2005) 102(49):17717-17722.

56. Brzozka K, Finke S, Conzelmann KK: Identification of the rabies virus alpha/beta interferon antagonist: Phosphoprotein $\mathbf{P}$ interferes with phosphorylation of interferon regulatory factor $3 . \mathrm{J}$ Virol (2005) 79(12):7673-7681.

57. Unterstab G, Ludwig S, Anton A, Planz O, Dauber B, Krappmann D, Heins $G$, Ehrhardt C, Wolff T: Viral targeting of the interferon-\{beta\}-inducing TRAF family member-associated NF-\{kappa\}B activator (TANK)-binding kinase-1. Proc Natl Acad Sci U S A (2005) 102(38):13640-13645.

58. Wu X, Qi X, Qu B, Zhang Z, Liang M, Li C, Cardona CJ, Li D, Xing Z: Evasion of antiviral immunity through sequestering of TBK1/IKKepsilon/IRF3 into viral inclusion bodies. J Virol (2014) 88(6):3067-3076.

59. Khaperskyy DA, Hatchette TF, McCormick C: Influenza A virus inhibits cytoplasmic stress granule formation. Faseb J (2012) 26(4):1629-1639.

60. Takeuchi K, Komatsu T, Kitagawa Y, Sada K, Gotoh B: Sendai virus C protein plays a role in restricting PKR activation by limiting the generation of intracellular double-stranded RNA. J Virol (2008) 82(20):10102-10110.

61. Boonyaratanakornkit J, Bartlett E, Schomacker H, Surman S, Akira S, Bae YS, Collins $P$, Murphy $B$, Schmidt A: The $C$ proteins of human parainfluenza virus type 1 limit double-stranded RNA accumulation that would otherwise trigger activation of MDA5 and protein kinase R. J Virol (2011) 85(4):1495-1506.

62. W.G. Davis, J.B. Bowzard, S.D. Sharma, M.E. Wiens, P. Ranjan, S. Gangappa, O. Stuchlik, J. Pohl, R.O. Donis, J.M. Katz, et al: The 3' 
33. Feng Q, Hato SV, Langereis MA, Zoll J, Virgen-Slane R, Peisley A, Hur $\mathrm{S}$, Semler BL, van Rij RP, van Kuppeveld FJ: MDA5 detects the double-stranded RNA replicative form in picornavirus-infected cells. Cell Rep (2012) 2(5):1187-1196.

34. Pichlmair A, Schulz O, Tan CP, Rehwinkel J, Kato H, Takeuchi O, Akira S, Way M, Schiavo G, Reis e Sousa C: Activation of MDA5 requires higher-order RNA structures generated during virus infection. $J$ Virol (2009) 83(20):10761-10769.

35. Luthra $P$, Sun $D$, Silverman $\mathrm{RH}$, He B: Activation of IFN- $\beta$ expression by a viral mRNA through RNase $L$ and MDA5. Proc Natl Acad Sci U $S A(2011)$ 108(5):2118-2123.

36. Rothenfusser S, Goutagny N, DiPerna G, Gong M, Monks BG, Schoenemeyer A, Yamamoto M, Akira S, Fitzgerald KA: The RNA helicase LGP2 inhibits TLR-independent sensing of viral replication by retinoic acid-inducible gene-i. J Immunol (2005) 175(8):5260-5268.

37. Venkataraman T, Valdes M, Elsby R, Kakuta S, Caceres G, Saijo S, Iwakura Y, Barber GN: Loss of DExD/H box RNA helicase LGP2 manifests disparate antiviral responses. J Immunol (2007) 178(10):6444-6455.

38. Ouda R, Onomoto K, Takahasi K, Edwards MR, Kato H, Yoneyama M, Fujita T: Retinoic acid-inducible gene i-inducible mir-23b inhibits infections by minor group rhinoviruses through down-regulation of the very low density lipoprotein receptor. J Biol Chem (2011) 286(29):26210-26219.

39. Patel JR, Jain A, Chou YY, Baum A, Ha T, Garcia-Sastre A: ATPase-driven oligomerization of RIG-I on RNA allows optimal activation of type-I interferon. EMBO Rep (2013) 14(9):780-787.

-• This paper describes the importance of ATPase-mediated RIG-I oligomerization in the optimal antiviral signaling.

40. Peisley A, Wu B, Yao H, Walz T, Hur S: RIG-I forms signaling-competent filaments in an ATP-dependent, ubiquitin-independent manner. Mol Cell (2013) 51(5):573-583.

- These studies suggest the importance of filament formation of RIG-I and MDA5 in RNA recognition and antiviral signaling.

41. Wu B, Peisley A, Richards C, Yao H, Zeng X, Lin C, Chu F, Walz T, Hur $S$ : Structural basis for dsRNA recognition, filament formation, and antiviral signal activation by MDA5. Cell (2013) 152(1-2):276-289.

- See annotation to Ref. [40“*]

42. Jiang X, Kinch LN, Brautigam CA, Chen X, Du F, Grishin NV, Chen ZJ: Ubiquitin-induced oligomerization of the RNA sensors RIG-I and MDA5 activates antiviral innate immune response. Immunity (2012) 36(6):959-973. 
-• This work report the significance of ubiquitin-mediated RLR oligomerization for IFN signaling.

43. Gack MU, Shin YC, Joo CH, Urano T, Liang C, Sun L, Takeuchi O, Akira S, Chen Z, Inoue S, Jung JU: TRIM25 ring-finger E3 ubiquitin ligase is essential for RIG-I-mediated antiviral activity. Nature (2007) 446(7138):916-920.

44. Oshiumi H, Miyashita M, Matsumoto $M$, Seya $T$ : A distinct role of Riplet-mediated K63-linked polyubiquitination of the RIG-I repressor domain in human antiviral innate immune responses. PLoS Pathog (2013) 9(8):e1003533.

45. Versteeg GA, Rajsbaum R, Sanchez-Aparicio MT, Maestre AM, Valdiviezo J, Shi M, Inn KS, Fernandez-Sesma A, Jung J, Garcia-Sastre A: The E3-ligase TRIM family of proteins regulates signaling pathways triggered by innate immune pattern-recognition receptors. Immunity (2013) 38(2):384-398.

46. Munir M, Berg M: The multiple faces of protein kinase $\mathbf{R}$ in antiviral defense. Virulence (2013) 4(1):85-89.

47. Onomoto K, Jogi M, Yoo JS, Narita R, Morimoto S, Takemura A, Sambhara S, Kawaguchi A, Osari S, Nagata K, Matsumiya T et al: Critical role of an antiviral stress granule containing RIG-I and PKR in viral detection and innate immunity. PLOS One (2012) 7(8):e43031.

-. This is the first paper describing the role of antiviral stress granule in RLR signal pathway.

48. Ng CS, Jogi M, Yoo JS, Onomoto K, Koike S, Iwasaki T, Yoneyama M, Kato $\mathrm{H}$, Fujita $\mathrm{T}$ : Encephalomyocarditis virus disrupts stress granules, the critical platform for triggering antiviral innate immune responses. J Virol (2013) 87(17):9511-9522.

49. Witteveldt J, Blundell R, Maarleveld JJ, McFadden N, Evans DJ, Simmonds P: The influence of viral RNA secondary structure on interactions with innate host cell defences. Nucleic Acids Res (2013).

50. Yoo JS, Takahasi K, Ng CS, Ouda R, Onomoto K, Yoneyama M, Lai JC, Lattmann S, Nagamine Y, Matsui T, Iwabuchi K et al: DHX36 enhances RIG-I signaling by facilitating PKR-mediated antiviral stress granule formation. PLoS Pathog (2014) 10(3):e1004012.

51. Hale BG, Randall RE, Ortin J, Jackson D: The multifunctional NS1 protein of influenza a viruses. J Gen Virol (2008) $89(\mathrm{Pt}$ 10):2359-2376.

52. Gack MU, Albrecht RA, Urano T, Inn KS, Huang IC, Carnero E, Farzan M, Inoue S, Jung JU, Garcia-Sastre A: Influenza a virus NS1 targets 
untranslated regions of influenza genomic sequences are 5'ppp-independent ligands for RIG-I, PLOS ONE (2012) 7:e32661.

63. L. Strahle, D. Garcin and D. Kolakofsky: Sendai virus defective-interfering genomes and the activation of interferon-beta,Virology 351 (2006) 101-111.

64. S. Deddouche, D. Goubau, J. Rehwinkel, P. Chakravarty, S. Begum, P. V. Maillard, A. Borg, N. Matthews, Q. Feng, F. J. M. van Kuppeveld et al: Identification of an LGP2-associated MDA5 agonist in picornavirus-infected cells, eLife 3 (2014) e01535.

65. M. Weber, A. Gawanbacht, M. Habjan, A. Rang, C. Borner, A. M. Schmidt, S. Veitinger, R. Jacob, S. Devignot, G. Kochs et al: Incoming RNA virus nucleocapsids containing a 5'-triphosphorylated genome activate RIG-I and antiviral signaling, Cell Host Microbe 13 (2013) 336-346.

66. M. Samanta, D. Iwakiri and K. Takada: Epstein-Barr virus-encoded small RNA induces IL-10 through RIG-I-mediated IRF-3 signaling, Oncogene 27 (2008) 4150-4160.

67. I. Satoshi, T. Makoto, O. Shinji, N. Yuichiro, N. Yoichi and Y. Yusuke: Both RIG-I and MDA5 RNA helicases contribute to the induction of alpha/beta interferon in measles virus-infected human cells, $J$ Virol 84 (2010) 372-379. 


\section{Cytoplasm}

\section{5'ppp RNA}

5'pppm

Inactive RLRs
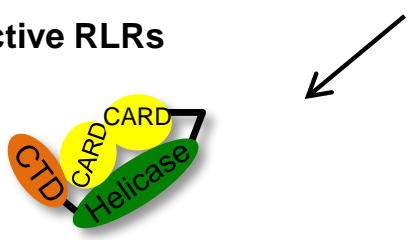

$$
\downarrow \begin{gathered}
\text { Conformation } \\
\text { Change }
\end{gathered}
$$

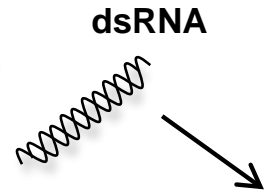

Active RLRs

$$
\sum \text { Virus }
$$


Table 1

\section{RLR agonists}

\begin{tabular}{lllll}
\hline RNA types & RNAs / Viruses & Characteristics & Sensor & References \\
& 5' ppp copy-back RNA & In vitro transcribed RNA & RIG-I & Schlee (2009), Schmidt (2009) \\
Artificial RNA & 5'ppp AU-rich RNA & Pol III product from poly dA:dT & RIG-I & Ablasser (2009), Chiu (2009) \\
& poly I:C short & Short dsRNA (<1 kb) & RIG-I & Kato (2008) \\
& poly l:C long & Long dsRNA (> 7 kb) & MDA5 & Kato (2008) \\
\hline & IAV genomic RNA & 5' ppp with panhandle structure & RIG-I & Rehwinkel (2010) \\
& HCV 3'UTR U/UC rich RNA & 5' ppp dependent & RIG-I & Saito (2008) \\
& IAV 3'UTR U/A rich RNA & 5' ppp independent & RIG-I & Davis (2012) \\
& SeV, VSV DI RNA & 5' ppp copy-back dsRNA & RIG-I & Strahle (2006), Patel (2013), Panda (2010) \\
& VV, EMCV & High molecular weight RNA & MDA5 & Pichlmair (2009) \\
& CVB3, Mengo & Replication intermediates & MDA5 & Feng (2012) \\
& PIV5 L mRNA & RNase L product & MDA5 & Luthra (2011) \\
& EMCV L antisense & LGP2-interacting RNA & MDA5 / LGP2 & Deddouche (2014) \\
\hline Host RNA & 5'OH-3'p short RNA & RNase L product & RIG-I/ MDA5 & Malathi (2007) \\
\hline
\end{tabular}


Table 2

List of viruses and their known sensors

\begin{tabular}{|c|c|c|c|}
\hline Sensor & Viruses & Families / Genome & References \\
\hline \multirow{6}{*}{ RIG-I } & $\begin{array}{l}\text { Newcastle disease virus } \\
\text { Sendai virus } \\
\text { Respiratory syncytical virus }\end{array}$ & Paramyxoviridae / (-) ssRNA, non-segmented & $\begin{array}{l}\text { Kato (2006) } \\
\text { Yoneyama (2004), Kato (2006) } \\
\text { Loo (2008) }\end{array}$ \\
\hline & $\begin{array}{l}\text { Vesicular stomatitis virus } \\
\text { Rabies virus }\end{array}$ & Rhabdoviridae / (-) ssRNA, non-segmented & $\begin{array}{l}\text { Yoneyama (2005), Kato (2006) } \\
\text { Hornung (2006) }\end{array}$ \\
\hline & $\begin{array}{l}\text { Influenza A virus } \\
\text { Influenza B virus } \\
\end{array}$ & Orthomyxoviridae / (-) ssRNA, segmented & $\begin{array}{l}\text { Kato (2006) } \\
\text { Loo (2008) }\end{array}$ \\
\hline & $\begin{array}{l}\text { Rift Valley fever virus } \\
\text { La Crosse virus }\end{array}$ & Bunyaviridae / (-) ssRNA, segmented & $\begin{array}{l}\text { Weber (2013) } \\
\text { Weber (2013) } \\
\end{array}$ \\
\hline & $\begin{array}{l}\text { Hepatitis C virus } \\
\text { Japanese encephalitis virus }\end{array}$ & Flaviviridae / (+) ssRNA, non-segmented & $\begin{array}{l}\text { Saito (2008) } \\
\text { Kato (2006) }\end{array}$ \\
\hline & Epstein-Barr virus & Gammaherpesviridae / dsDNA & Samanta (2008) \\
\hline \multirow[t]{3}{*}{ MDA5 } & $\begin{array}{l}\text { Encephalomyocarditis virus } \\
\text { Theiler's murine encephalitis virus } \\
\text { Mengovirus } \\
\text { Coxackie virus } \\
\text { Entero virus } \\
\text { Human Parechovirus } \\
\text { Equine Rhinitis A virus } \\
\text { Saffold virus }\end{array}$ & Picornaviridae / (+) ssRNA, non-segmented & $\begin{array}{l}\text { Kato (2006) } \\
\text { Kato (2006) } \\
\text { Kato (2006) } \\
\text { Feng (2012) } \\
\text { Feng (2012) } \\
\text { Feng (2012) } \\
\text { Feng (2012) } \\
\text { Feng (2012) }\end{array}$ \\
\hline & Norovirus & Caliciviridae / (+) ssRNA, non-segmented & McCartney (2008) \\
\hline & Vaccinia virus & Poxviridae / dsDNA & Pichlmair (2009) \\
\hline \multirow{3}{*}{ RIG-I / MDA5 } & $\begin{array}{l}\text { Westnile virus } \\
\text { Dengue viurs }\end{array}$ & Flaviviridae / (+) ssRNA, non-segmented & $\begin{array}{l}\text { Loo (2008) } \\
\text { Loo (2008) }\end{array}$ \\
\hline & Measles virus & Paramyxoviridae / (-) ssRNA, non-segmented & Satoshi (2010) \\
\hline & Semliki forest virus & Togaviridae $/(+)$ ssRNA, non-segmented & Schulz (2010) \\
\hline
\end{tabular}

